\title{
LA CONSERVACION DE LAS EDIFICACIONES EN LA LEGISLACION DE PROTECCION DEL PATRIMONIO HISTORICO *
}

\author{
POR \\ TOMÁS QUINTANA LÓPEZ \\ Profesor titular de Derecho Administrativo
}

\begin{abstract}
SUMARIO: ConsiderACIONES PREVIAS.-ANTECEDENTES DE LA LEY 16/1985, DE 25 DE JUNIO.-EL IMPULSO CONSTITUCIONAL.-LA LEY 16/1985 DE 25 DE JUNIO: 1. Inmuebles integrantes del Patrimonio Histórico no declarados de interés cultural. 2. Los inmuebles de interés cultural: 2.1 Monumentos. 2.2 Los conjuntos históricos.Declaración de ruina y protección del Patrimonio histórico.-Valoración.
\end{abstract}

\section{CONSIDERACIONES PREVIAS}

En adelante, trataremos de encontrar en la normativa de protección del Patrimonio Histórico Español otro contrapunto a la política de demolición-renovación a que antes nos hemos referido.

Esta normativa, bien es conocido que forma un dispositivo de añejo arraigo en nuestro ordenamiento, cuyas primeras manifestaciones se remontan al medievo, más por el carácter defensivo de las murallas y otras obras que por su valor histórico-artístico, encontrando más tarde y para siempre en la Corona española un adalid de su defensa (1); no nos vamos a detener, por razones obvias, sin embargo, en el devenir histórico de esta legislación (2). Tampoco es éste según entendemos, el lugar adecuado para hacer un análisis exhaustivo de esta normativa de tutela, recientemente renovada, y sobre la que ya es posible encontrar en nuestra literatura jurídica interensantísimas aportaciones (3); por el contrario, el alcance del estudio que aquí se va a hacer estará limitado por el objeto que justifica esta parte del trabajo, es decir, por el análisis

- Este trabajo forma parte de otro más amplio que con el título La conservación de las ciudades en el moderno urbanismo aparecerá en breve como libro, circunstancia que explica las referencias bibliográficas incompletas. Aprovecho para reiterar mi agradecimiento al Instituto del Territorio y Urbanismo por la Ayuda a la Investigación otorgada, sin la cual no hubiera podido realizar el trabajo.

(1) Cfr. GARCIA-ESCUdero, P. y PEndAs GaRcia, B.: El nuevo régimen juridico del Patrimonio Histórico Español, Ministerio de Cultura, Madrid, 1986, pp. 27 y 28.

(2) Vid., las páginas citadas de la obra anterior; también, con la misma finalidad puede consultarse, GONZÁlEZ-UBEDA RICO. G.: Aspectos juridicos de la protección del patrimonio histórico-artístico y cultural, Ministerio de Cultura, pp. 25 y ss.

(3) GARCIA-ESCUdeRo y PENDAS GaRCIA: El nuevo régimen.... cit. Más recientemente. BASSOLS COMA: "El Patrimonio Histórico Español. Aspectos de su régimen juridico», en RAP. núm. 114, pp. 93 y 22.

REVISTA DE ESTUDIOS. -9 
de los instrumentos de que dispone nuestro Derecho al servicio de la conservación de lo edificado; además, en este caso, por la recientísima reforma de este sector del ordenamiento, realizada hace tres años, se han de intentar esclarecer de forma un tanto especulativa, las posibilidades que ofrece esta normativa renovadora.

\section{ANTECEDENTES DE LA LEY 16/1985, DE 25 DE JUNIO}

A nuestros efectos no tendría demasiado interés extendernos en el estudio de la legislación republicana sobre el Patrimonio Histórico, que, por otra parte, dada su longevidad e importancia, ha ocupado a una amplia lista de autores (4). Sin embargo, sí creo oportuno, aún a riesgo de ser reiterativo, reparar en algunas cuestiones que habiendo sido abordadas puntualmente por la doctrina, mantienen en nuestro caso un doble interés: primero, por ilustrar la falta de eficacia de esta normativa para servir a la conservación del patrimonio edificado demostrada durante los años en que ha estado vigente, $y$, además, porque la legislación recientemente estrenada trata de dar respuesta a estas carencias.

Como se ha señalado, la Ley de 13 de mayo de 1933, de Defensa, Conservación y Acrecentamiento del Patrimonio Histórico-Artístico Nacional, tiene en el Real Decreto-ley de 9 de agosto de 1926 su antecedente más inmediato (5), norma a la que hay que contabilizar en su haber la inclusión en el Tesoro Artístico Nacional, junto a las edificaciones aisladas, los conjuntos de ellas, sitios y lugares de reconocida y peculiar belleza, cuya protección y conservación sean necesarios para mantener el aspecto típico, artístico y pintoresco característico de España; acierto al que hay que añadir una serie de previsiones para coordinar la protección sectorial de aquéllos con los incipentes instrumentos de planeamiento. No obstante, estas iniciativas pronto quedaron truncadas

(4) Sin ánimo de ofrecer una lista completa de autores y obras, pueden verse: GómEZ ANTÓN, F.: "Tres disposiciones sobre exportación de bienes de interés artístico o histórico», en RAP, núm. 33, pp. 251 y ss.; TAMAYO ISASI-ISASMENDI, J. A.: "La comisión de expropiación de bienes de valor artístico o arqueológico», en RAP, núm. 47, pp. 95 y ss.; RODRIGUEZ MORO, N.: "Defensa de los valores históricos, artísticos, típicos y turísticos de carácter local», en $R E V L$, núm. 144, pp. 801:y ss.; MARTIN MATEO: "La propiedad monumental», en RAP, núm. 49, pp. 49 y ss.; ALVAREZ ALVAREZ, J. L.: El patrimonio artístico español, Miñón, Valladolid, 1975; ROCA ROCA: El patrimonio artístico y cultural, IEAL, Madrid, 1976; ESTRELLA IZOUIERDO, V.: "EI patrimonio histórico-artístico en la jurisprudencian, en RAP, núm. 76 , pp. 133 y ss.; FERNÄNDEZ RODRIGUEZ: "La legislación española sobre patrimonio histórico-artístico. Balance de la situación de cara a su reforma», en RDU, núm. 60, pp. 13 y ss.; BENITEZ DE LUGO Y GUILLÉN F.: "EI patrimonio Histórico-Artístico-Cultural y el-Medio Ambiente», en $R D U$, núm. 83, pp. 41 y 11 ; GONZÁLEZ-UBEDA RICO: Aspectos jurídicos...; cit.

(5) FERNÁNDEZ RODRÍGUEZ: «La legislación española...». cit., p. 16. 
por obra de la Ley de 13 de mayo del 33; en efecto, según advirtió Martín Mateo, pese a que esta Ley reconocía la existencia de estos conjuntos, lo cierto es que fueron sometidos a la misma regulación que los monumentos histórico-artísticos considerados aisladamente (6). Por otra parte, incurre también en el error de no dar entrada a ninguna medida de coordinación entre las técnicas típicas de la normativa de defensa del patrimonio histórico y el urbanismo, desconocimiento que tres años más tarde se trataba de mitigar por vía administrativa con la aprobación del Reglamento de 16 de abril de 1936, al disponer que las reformas y ensanches, en cualquier caso, habrár: de respetar los monumentos histórico-artísticos (7).

Esta disfunción ha sido, sin duda, una de las causantes de la inadecuada protección a que se ha visto sometida la riqueza monumental en nuestro país, y ello pese a que intuitivamente pronto fue advertido por algún autor (8), habiendo de esperar a que, ya más recientemente, fueran constatadas con absoluta meticulosidad todas las consecuencias negativas que se derivan de la desconexión de los dos ordenamientos -el histórico-artístico y el urbanístico- (9) para que el legislador tomara conciencia de la necesidad de trabar, mediante los mecanismos oportunos, tanto las instituciones procedentes de ambas normativas como las Administraciones públicas llamadas a aplicarlas (10).

No se deben, sin embargo, imputar totalmente los pobres resultados obtenidos a la falta de coordinación. A la ausencia de

(6) MARTIN MATEO: "La propiedad...", cit., p. 97.

(7). FERNÁNDEZ RODRíGUEZ: "La legislación española...», cit., pp. 18 y 19.

(8) Ya en 1966, MARTIN MATEO afirmaba: «... no resulta aconsejable la adopción de medidas que mutuamente desconozcan los problemas de la tutela monumental y los problemas de la ordenación urbana... Parece, en todo caso, que debe prevalecer la técnica planificadora y ordenadora que representa la Ley del Suelo y que lo procedente es realizar la planificación especial que para estos efectos en la misma se prevé, dando una intervención más decisiva y amplia que las que les reserva la Ley, a los órganos de tutela monumental en el período de formación o integración de los planes a quienes desde luego incumbirá la vigilancia y protección de las obras y proyectos que se realicen en monumentos singularmente declarados como tales. La tutela monumental tradicional está pensada fundamentalmente para estos supuestos y no es posible, como la actividad normativa del organismo competente viene atestiguando, hacerse efectiva sobre núcleos o sectores urbanos completos sin recurso a la técnica del plan y de las ordenanzas de edificación...», "La propiedad...», cit., pp. 98 y 99.

(9) La realidad fue agudamente captada por FERNÁNDEZ RODRIGUEZ, recogiendo incluso la jurisprudencia del Tribunal Supremo que ilustra la situación, "La legislación española...", cit., pp. 27 y 28 , abogando en aquel momento por la necesidad de uplantearse seriamente el problema de la coexistencia de dos ordenamientos que se ignoran (con la única salvedad de la exigencia de dos autorizaciones diferentes - la licencia thunicipal y la aprobación de Bellas Artes-, recordada por la Circular de la Dirección General de Administración Local de 18 de abril de 1967) $y$ de regularizar las relaciones de dos órdenes competenciales que permanecen incomunicados» (p. 19).

(10) En el trabajo que se viene citando, publicado en 1978, FERNÁNDEZ RODRIGUEZ observa que el anteproyecto de Ley del Patrimonio aún carece de las suficientes conexiones con el ordenamiento urbanístico (p. 35). La Ley actualmente vigente, como se verá más adelante, supera el mutuo desconocimiento tradicional entre ambos ordenamientos. 
mecanismos técnicos precisos para integrar en el planeamiento urbanístico la defensa del Patrimonio Histórico, hay que unir otras circunstancias perfectamente identificadas en su momento por la doctrina, como la falta de voluntad por parte del Estado para hacer frente a los cuantiosos gastos que necesariamente se derivan de esta acción protectora, o la incoherencia, siempre desde la perspectiva de esta labor tuitiva, que indirectamente induce al propietario a la desidia (11).

Hecho este brevísimo excurso por la normativa de protección del Patrimonio Histórico, gestada a partir de 1933, parece obligado concluir, que las circunstancias sumariamente descritas han sido un pesado lastre para la eficacia de este sector del ordenamiento. Con todo, y ahora ya bajo la perspectiva que preside este trabajo, desde este momento hay que señalar que, aun en el hipotético caso de que no se hubiera manifestado con tanta radicalidad la incomunicación entre estos dos ordenamientos, ni hubiera sido posible achacar durante el largo período de vigencia de la Ley de 1933, la falta de sensibilidad observada por los poderes públicos, incapaces de trasladar partidas presupuestarias a estos efectos, aún haciendo abstracción de estas circunstancias, hay que señalar que el legislador, obediente al objetivo con que se enfrentó, limitó de forma muy selectiva la aplicación del acervo de medidas tuitivas, por lo que a nosotros interesa, a cuantos inmuebles de interés artístico, arqueológico, paleontológico o histórico que haya en España de antigüedad no menor de un siglo, o bien, sin este requisito temporal, cuando tuvieran un valor artístico o histórico indiscutible y como tal hayan sido declarados. De todo ello cabe deducir, que esta normativa, por unas $y$ otras circunstancias, se ha mantenido prácticamente al margen del proceso de deterioro y destrucción de nuestros centros urbanos.

\section{EL IMPULSO CONSTITUCIONAL}

También en esta materia la Constitución ha comprometido a los Poderes públicos. En efecto, su artículo 46 (12), con el precedente de otras Constituciones europeas de cercana cronología (13), les encargó garantizar la conservación y promoción del enriqueci-

(11) Vid. MARTin MATEO: "La propiedad...., cit., p. 96.

(12) Sobre su elaboración y debates parlamentarios, vid., ENTRENA CUESTA, R.: "Artículo 46i). Comentarios a la Constitución, dirigidos por GARRIDO FALLA, Civitas. Madrid. 1985. pp. 826 y 827. PÉREZ LUÑo A.: "Artículo 46, Patrimonio Histórico, Artistico y Cultural», Comentarios a las Leyes Políticas, dirigidos por AlzAgA VILLAAMii., Edersa, Madrid, 1984. pp. 294 y ss.

(13) Vid. PÉREZ LuÑo: Comentarios..., cit., pp. 288 y 289. 
miento del Patrimonio Histórico, Cultural y Artístico de los pueblos de España y de los bienes que lo integran.

Se ha destacado, justamente, que la posición adoptada por nuestro constituyente se aleja de la concepción aislacionista tradicional en la defensa del patrimonio histórico, optando, por el contrario, en favor de la protección de todo su entorno (14), lo cual, a nuestros efectos; tiene gran importancia. Junto a este dato, también se ha mantenido la integración de esta labor tuitiva en el marco más amplio del desarrollo de la cultura (15), que los poderes públicos también tienen que promover y tutelar para que todos puedan acceder a ella. Estas certeras consideraciones, que la doctrina ha venido realizando, avalan y exigen del Estado una intensa actuación que ha de proyectarse sobre el patrimonio histórico, que no sólo abarque la conservación e incluso la promoción del enriquecimiento, como textualmente prevé el artículo 46 del texto constitucional, sino que obliga a los Poderes públicos a acercar a todos - tutelas el acceso a la cultura- los elementos integrantes del patrimonio histórico, cultural y artístico.

Las consecuencias que se derivan de esta esencial dimensión cultural del legado histórico precisan de unos apoyos dogmáticos que expliquen la posición de disfrute a que tienen derecho los ciudadanos sobre los bienes que componen este patrimonio heredado, máxime cuando éste puede estar en manos privadas, disfrute que es ínsito al acceso a la cultura a que todos tenemos constitucionalmente derecho. Con este planteamiento, enseguida se advertirá el conflicto a que da lugar la satisfacción de este derecho: la concepción tradicional de la propiedad privada aplicada al patrimonio histórico puede llegar a convertirse en un obstáculo difícilmente superable para los poderes públicos constitucionalmente vinculados en los términmos que hemos expuesto. Las dificultades que apuntamos no singularizan a nuestro país; ahi está la conocida doctrina de los «Beni Culturali», que, con base en la distinción entre lo material y lo inmaterial del bien cultural, defiende la concurrencia y compatibilidad de un doble uso a determinar por el legislador: el del propietario, derivado de su título dominical, sobre el soporte material del bien cultural, y el goce que corresponde a la colectividad sobre el propio bien cultural. No vamos a insistir en los pormenores de esta doctrina, formúlada hace algunos años en Italia $y$ que ha tenido una gran acogida entre nosotros (16).

(14) Pérez luño: Comentarios..., cit., p. 297.

(15) GARCiA ESCUDERO y PENDAS GARCiA: El nuevo régimen..., cit., p. 59.

(16) Es sabido que la doctrina de los "Bene Culturale e Ambientale» está en el informe emitido por la Comisión Francesceschini, constituida en 1964 en Italia, a partir del cual algunos autores han realizado su formulación; M. S. GIANNINI: «I beni culturali», en RTDP, 1976, pp. 3 
Sí es oportuno, no obstante, advertir que ya el legislador del 33 reconoció el derecho al goce colectivo de los inmuebles sujetos a esa Ley, independientemente del sujeto que fuera su titular (17), derecho que la doctrina italiana ha situado en la base de los que denomina bienes culturales. Previsiones similares y más precisas contiene hoy la nueva Ley del Patrimonio Histórico Español (18), la cual, además, haciéndose eco del rótulo bajo el que fue rubricada esta doctrina, elevó a la categoría de bienes de especial protección los reconocidos de interés cultural, quedando sometidos a una intervención muy intensa de los poderes públicos, de acuerdo con la teoría de la propiedad dividida que sustenta la doctrina de los bienes culturales (19).

Para terminar, conectando ahora con la opción que, según se ha señalado anteriormente, contiene el texto constitucional al imponer la integración del edificio aislado en su entorno, adelantamos que se abre paso con renovado vigor la función del urbanismo y de sus instrumentos característicos, los planes, en la defensa del patrimonio histórico español, tema éste sobre el que incidiremos después.

\section{LA LEY 16/1985, DE 25 DE JUNIO}

Con la promulgación de esta Ley y del Real Decreto 11/1986, de 10 de enero, que la desarrolla parcialmente, se inicia en España

y ss.; T. ALIBRANDI y P. FERRI: I beni Culturali e Ambientali, Giuffrè, Milano, 1978; N. GRECO: Stato di cultura e gestioni dei beni culturali, il Mulino, Bologna, 1981. En España esta doctrina ha tenido un importante eco, vid., por ejemplo: SÁNCHEZ BLANCO, A.: La afectación de bienes de dominio público, IGO, Sevilla, 1979, pp. 287 y ss.; LÓPEZ RAMÓN: La conservación de la naturaleza: los espacios naturales protegidos, Bolonia, 1980, pp. 284 y ss.; GARCIA DE ENTERRIA: "Consideraciones sobre una nueva legislación del patrimonio artístico, histórico y cultural», en REDA núm. 39, pp. 575 y ss. Por nuestra parte, hemos propuesto la viabilidad de esta doctrina para otorgar protección integral al medio ambiente natural, vid., QUINTANA LÓPEZ: La repercusión de las actividades mineras en el medio ambiente. Su tratamiento jurídico, Montecorvo, Madrid; 1987, pp. 44 y ss. y 67 y 68.

(17) El artículo 29 de la Ley de 13 de mayo de 1933 disponía: «Los organismos oficiales y las entidades civiles y eclesiásticas, de cualquier clase que sean, tienen la ineludible obligación de permitir, cuatro veces al mes y en dias y horas previa y públicamente señalados, la contemplación, el estudio y la reproducción fotográfica o dibujada de los inmuebles sujetos a esta Ley que les pertenezcan o que tengan en posesión... Los particulares y las personas jurídicas poseedoras de inmuebles declarados monumentos histórico-artisticos, tendrán la misma obligación.»)

(18) Artículo 13.2: "Asimismo, los propietarios y, en su caso, los titulares de derechos reales sobre tales bienes, o quienes los posean por cualquier título, están obligados a permitir y facilitar su inspección por parte de los organismos competentes, su estudio a los investigadores, previa solicitud razonada de éstos, y su visita pública, en las condiciones de gratuidad que se determinen reglamentariamente, al menos cuatro dias al mes, en días y horas previamente señalados. El cumplimiento de esta última obligación podrá ser dispensado total o parcialmente por la Administración competente cuando medie causa justificada. En el caso de bienes muebles se podrá igualmente acordar como obligación sustitutoria el depósito del bien en un lugar que reúna las adecuadas condiciones de seguridad y exhibición durante un período máximo de cinco meses cada dos años.»

(19) Cfr. García ESCUdero y Pendas García: El nuevo régimen..., cit., p. 144. 
una nueva andadura en la protección de nuestro patrimonio histórico; de ellos se intentará dar cuenta en la medida en que, con su concurso, sea posible abordar, aunque sea limitadamente, la conservación de la riqueza inmobiliaria del país. No nos detendremos en las cuestiones que con carácter general regula esta reciente normativa, tales como las medidas de fomento o las infracciones administrativas $y$ sus sanciones, cuestiones que, además de exceder del objetivo que con este trabajo se pretende, han sido ya analizadas de forma pormenorizada por la doctrina (20).

El punto de partida de la reciente Ley se sitúa en la descripción de bienes que integran el Patrimonio Histórico Español, descripción muy amplia, que rebasa los límites de la Ley precedente. Con todo, por razones obvias, nuestro análisis se va a limitar a los preceptos que incidan sobre el patrimonio inmobiliario, y dentro de él, solamente aquellos conceptos que nos remitan al objetivo del presente trabajo. Circunscrito nuestro estudio a los bienes inmuebles integrantes del patrimonio histórico, es oportuno tener en cuenta que el legislador, obediente a la tradición, sitúa el dispositivo normativo más intenso -siempre atendiendo a lo que constituye el objetivo de nuestro estudio- sobre los inmuebles declarados de interés cultural, que necesariamente habrán de tener alguna de las siguientes categorías: monumentos, jardines, conjuntos, sitios históricos y zonas arqueológicas. En cualquier caso, ni siquiera todas estas categorías son de nuestro interés; de acuerdo con la definición que el propio texto legal nos proporciona de cada una de ellas (art. 15), solamente los monumentos y los conjuntos históri$\cos (21)$, su protección y enriquecimiento, tienen una importante repercusión en la conservación del patrimonio urbano edificado, cuestión sobre la que versa el trabajo en su integridad.

Las previsiones de la Ley del Patrimonio Histórico Español no se limitan, sin embargo, a los inmuebles declarados de interés cultural; en efecto, el legislador, conectando con una progresiva jurispruden-

(20) Vid., GARCIA ESCUdeRo y PENDAS GARCia: El nuevo régimen..., cit., pp. 213 y ss. Sólo añadir que con las medidas de fomento que ahora se prevén, el legislador parece haber tenido en cuenta la experiencia negativa surgida de la legislación anterior, carente de un dispositivo preciso de apoyo económico a los propietarios de bienes que por su valor histórico-artístico era preciso conservar.

(21) Articulo 15.1: "Son monumentos aquellos bienes inmuebles que constituyen realizaciones arquitectónicas o de ingeniería u obras de escultura colosal, siempre que tengan interés histórico, artístico, científico o social.».

Artículo 15.3: "Conjunto histórico es la agrupación de bienes inmuebles que forman una unidad de asentamiento, continua o dispersa, condicionada por una estructura física representativa de la evolución de una comunidad humana por ser testimonio de su cultura o constituir un valor de uso y disfrute para la colectividad. Asimismo, es conjunto histórico cualquier núcleo individualizado de inmuebles comprendidos en una unidad superior de población que reúna esas mismas características y pueda ser claramente delimitado.» 
cia detectada oportunamente por Sosa Wagner (22), extiende algunas medidas tuitivas a inmuebles integrantes del Patrimonio Histórico no declarados de Interés Cultural. A todas estas categorías, al estudio de los instrumentos de protección que se configuran en la Ley y a su incidencia en la conservación integral del patrimonio edificado, dedicaré las páginas que siguen.

\section{Inmuebles integrantes del Patrimonio Histórico no decla- rados de Interés Cultural}

Se acaba de adelantar que el grueso de previsiones tuitivas relativas a inmuebles contenidas en la Ley del Patrimonio Histórico Español, afectan a los declarados de Interés Cultural; no obstante, manejando un concepto amplio de Patrimonio Histórico, el legislador ha dispuesto algunas medidas referidas a otros inmuebles, de entre ellos merece destacar que «el Organismo competente podrá ordenar la suspensión de las obras de demolición total o parcial o de cambio de uso de los inmuebles integrantes del Patrimonio Histórico Español no declarados de Interés Cultural» (artículo 25). suspensión que a modo de medida cautelar, paraliza las obras de demolición o el cambio de uso durante un plazo máximo de seis meses, plazo en el que la Administración urbanística ha de resolver sobre la procedencia de la aprobación inicial de un plan especial o de otras medidas de protección de las previstas en la legislación urbanística.

Por vez primera, con los limitados antecedentes contenidos en la legislación anterior, a que hemos hecho referencia, el legislador del ochenta y cinco ha tenido en cuenta aquellos inmuebles que, aun no habiendo sido objeto de declaración formal como de Interés Cultural, reúnen caracteres artísticos, históricos, paleontológicos, arqueológicos, etnológicos, científicos o técnicos, que les hacen

(22) Asi se manifestaba este autor hace ahora casi diez años: "Superponiéndose a esta técnica de pequeña jurisprudencia, cuyo interés es creciente como he dicho en otras ocasiones, ha desempolvado un instrumento mucho más contundente: sin existir declaración de Monumento Histórico-Artístico, sin que ni siquiera se haya iniciado el correspondiente expediente, pueden suspenderse aquellas obras que estén referidas a edificios de los que se tenga constancia que pueden revestir un valor histórico-artístico, aunque aún, insisto, no haya habido pronunciamiento previo de la Administración.» Vid. SOSA WAGNER, F.: "Suspensión de obras, licencias de derribo y defensa del patrimonio histórico-artístico», en REDA, núm. 21, p. 271. Las afirmaciones de Sosa están avaladas por dos sentencias de las Salas de lo contencioso de Albacete (26 de mayo de 1978) y de Valencia (9 de diciembre de 1977), respectivamente, que mantienen la obligación del órgano competente (autoridad municipal) de adoptar medidas tuitivas con relación a edificios sobre los que no sólo no exista declaración de monumento histórico-artístico, sino que ni siquiera había sido incoado el expediente de declaración, trámite éste al que ya el artículo 17 de la Ley de 13 de mayo de 1933 vinculaba la imposibilidad del derribo del edificio o de realizar obras en él. 
susceptibles de integrar el Patrimonio Histórico Español; de su protección, sin embargo, la organización del Patrimonio Histórico se desentiende, toda vez que el artículo 25 de su Ley reguladora se remite a lá Administración competente en materia urbanística para que sea ésta la que apruebe, si lo considera oportuno, un plan especial u otras medidas de protección de las previstas en la. legislación de los edificios protegibles. En definitiva, la remisión a que se alude conduce al ordenamiento urbanístico, a alguno de los instrumentos de que dispone éste para proteger el Patrimonio Histórico-Artístico.

A la vista de lo expuesto, cabe hacerse la siguiente pregunta: ¿supone un avance la regulación dada al artículo 25?, la respuesta, aunque admita algún matiz, entiendo que ha de ser negativa, dado que no contiene novum alguno en relación con la legislación urbanística a que se remite, pues la aprobación inicial de un plan especial o la adopción de otras medidas previstas en la legislación urbanística, desde luego, podrán ser hechas efectivas con posterioridad a la promulgación de la Ley 16/1985, a lo que coadyuva el mentado artículo 25, pero también podrían haberlo sido con anterioridad, pues nada impedía, sino todo lo contrario, que la Administración urbanística pudiera proteger el Patrimonio Histórico-Artístico mediante la aprobación de un plan especial con su catálogo correspondiente, o bien aprobar éste al margen de aquél, según admite el artículo 86 del Reglamento de Planeamiento, o adoptando cualquier otra medida de las previstas en la legislación urbanística.

El contenido del artículo 25 no es, sin embargo, indiferente; en efecto, en primer lugar, supone un dies ad quem para la Administración urbanística, dado que la suspensión de las obras de demolición o del cambio de uso ordenada por el organismo competente para la protección del Patrimonio Histórico expira a los seis meses, plazo en el que la Administración urbanística habrá de aplicar la legislación del suelo en los términos vistos. Con todo, esto no es lo más destacable de la previsión; a mi modo de ver, lo importante es el lazo que tiende esta legislación especial al ordenamiento urbanístico, por lo que, en este precepto, es posible localizar ya una conexión entre ambos ordenamientos -no la única, según se verá-, tan poco frecuentes en la legislatión vigente hasta 1985 y reiteradamente hechas notar por nuestra doctrina como más arriba se ha señalado.

A tenor del artículo 25 in fine, la resolución que adopte la Administración urbanística deberá ser comunicada al organismo que hubiera ordenado la suspensión, sin que ello impida el ejercicio de la potestad prevista en el artículo 37.2. La resolución a que se 
refiere el último párrafo del artículo 25 ha de versar sobre la procedencia del plan especial u otras medidas previstas en la legislación urbanística, disposición que nos pone frente a otra actuación relativamente novedosa a realizar por la Administración de protección al Patrimonio Histórico en inmuebles no declarados de Interés Cultural, «siempre que se aprecie la concurrencia de alguno de los valores a que hace mención el artículo 1 de esta Ley», consistente en impedir el derribo y suspender cualquier clase de obra o intervención, para, en el plazo de treinta días hábiles, permitir la continuación de la obra iniciada o incoar la declaración del Interés Cultural de aquél (art. 37.2) (23).

También en relación con los inmuebles integrantes del Patrimonio Histórico sobre los que se ha incoado un expediente de declaración, el artículo 16 dispone que quedarán en suspenso las correspondientes licencias municipales de parcelación, edificación o demolición en las zonas afectadas, así como los efectos de las ya otorgadas; incluso las obras que hubieran de realizarse por razón de fuerza mayor precisarán la autorización de los órganos competentes para la ejecución de la Ley del Patrimonio Histórico Español. La suspensión $y$, aunque no se dice expresamente, también la autorización sectorial, dependerá de la resolución o, en su caso, caducidad del expediente, por lo que el artículo 16 tiene un carácter cautelar en la misma línea que su antecedente, el artículo 17 de la Ley de 1933.

\section{Los inmuebles de Interés Cultural}

La Ley del Patrimonio Histórico Español pivota en gran parte sobre la declaración de ciertos Bienes de Interés Cultural; de todos ellos, por razones ya apuntadas, sólo nos ocuparemos de los monumentos y de los conjuntos históricos. En cualquier caso, desde ahora parece oportuno hacerse eco de la afirmación contenida en el artículo 18 que afecta a todos los inmuebles que han sido objeto de esa declaración; me refiero a la inseparabilidad de su

(23) Esta previsión, y de ahí su relativa novedad, conecta con la tesis mantenida por la Sala de lo contencioso de la Audiencia Territorial de Valencia en su sentencia de 9 de diciembre de 1977 (núm. 3337, Jurisdicción Contencioso-Administrativa, sentencias Je las Audiencias, año 1978) cuando afirma que: «... dentro de las atribuciones del Alcalde, consigna la de velar por la conservación de los castillos, monumentos nacionales, edificios artísticos o históricos y belleza del paisaje', atribuciones que lógicamente han de referirse, no ya sólo a los inmuebles declarados monumentos nacionales, sino también a aquellos otros que no estén en dicha situación pero que, por informaciones obtenidas o características propias de los mismos, puede fundadamente esperarse que lo sean, toda vez que, de no ser así, se malograría la mayor parte de las veces la conservación y subsistencia de tales edificaciones y se haría prevalecer el interés particular o individual sobre el general $y$ colectivo cuando el ordenamiento brinda sobrados medios al primero para su adecuada y justa compensación. 
entorno, aspiración reiterada por la doctrina (24), que por fin encuentra su cauce en algunos preceptos de la nueva Ley; a ello estarán dedicadas las páginas que siguen fundamentalmente.

\subsection{MONUMENTOS}

Para ellos, el artículo 19 prevé las tradicionales limitaciones: «no podrá realizarse obra interior o exterior que afecte directamente al inmueble $o$ a cualquiera de sus partes integrantes o pertenencias sin autorización expresa de los organismos competentes para la ejecución de esta Ley», limitación que se extiende en los mismos términos a la realización de obras en el entorno afectado por la declaración. Nada hay de novedoso en esta prescripción si la comparamos con el contenido del artículo 23 de la Ley de 1933, incluso la extensión de las limitaciones al entorno, aunque con distinta redacción, también estuvo presente en el artículo 6 del Decreto de 22 de julio de 1958, previsión que, por cierto, suscitó algunas críticas (25).

La competencia, pues, para autorizar obras en los monumentos o en su entorno, corresponde hoy, como en el pasado, a los organismos de ejecución de la Ley. La previsión, si bien es perfectamente lógica en relación a monumentos individualmente considerados, parece que lo es menos cuando se trata de realizar obras en su entorno, pues el tratamiento conjunto a que nos remite el entorno exige técnicas globalizadoras como las que dispone el ordenamiento urbanístico, por lo que, en este caso, quizás debería verse alterada la competencia en favor de la Administración urbanística. Con todo, lo cierto es que cuando la declaración de Bien de Interés Cultural recae sobre un monumento, también las obras de su entorno se ven limitadas, sin que, como el legislador ha dispuesto para otros casos, sea preceptiva la redacción de instrumento de planeamiento alguno sobre el inmueble y el área afectada; ello, sin embargo, no es óbice para que, potestativamente, sea aprobado el plan correspondiente, pues ni está prohibido en parte alguna de nuestro ordenamiento y sí, por el contrario, está admitido tácitamente en el artículo 20.4; en efecto, este precepto de nuevo reitera la competencia de la Administración sectorial del Patrimonio Histórico para autorizar - de forma acumulativa a la licencia municipal- las obras que afecten a monumentos (y jardines históricos), aun en el caso de que se haya aprobado definitivamente un plan especial de protección del área afectada u otro instrumento de planeamiento de los previstos en la legislación

(24). FERNÁNDEZ RODRIGUEZ: "La legislación española...», cit., pp. 20 y ss.

(25) FERNÁNDEZ RODRIGUEZ: "La legislación española...», cit., pp. 23 y 24. 
urbanística. De todo ello, lo que nos interesa destacar es que la redacción de un plan urbanístico no enerva en absoluto la competencia de los órganos de protección del Patrimonio Histórico para autorizar obras que afecten a monumentos o a su entorno, lo cual, pensando en los alrededores del monumento, parece desacertado, pues refleja un recelo del legislador hacia el urbanismo $y$, en este caso, hacia la Administración municipal encargada de otorgar las licencias de obras que, de extenderse a todos los sectores incidentes en el territorio, terminaría por hacer desaparecer el urbanismo y sus técnicas peculiares, los instrumentos de planeamiento, tan trabajosamente alumbradas a lo largo del tiempo. La solución más idónea, en nuestro criterio, debería haber distinguido entre monumentos y su entorno, pues si en los primeros está justificada una intervención más intensa -mediante la técnica de la autorizatoria- de la Administración del Patrimonio Histórico, nada justifica que existiendo un plan aprobado definitivamente, su entorno, las obras que en él se realicen, deban ser autorizadas por los mismos organismos sectoriales y no exclusivamente por la Administración municipal, llamada, con carácter general, a hacer aplicación de aquél.

\subsection{LOS CONJUNTOS HISTÓRICOS}

La redacción de un plan especial de protección o cualquier otro instrumento urbanístico de planeamiento se torna preceptiva ante la declaración de un Conjunto Histórico (también sitio histórico y zona arqueológica). Para ellos el legislador ha previsto unos contenidos mínimos y unos principios que en todo caso el plan deberá asumir; los primeros son: el plan establecerá para todos los usos públicos el orden prioritario de su instalación en los edificios y espacios que sean aptos para ello, contemplará las posibles áreas de rehabilitación integrada (26) que permitan la recuperación del área residencial y de las actividades económicas adecuadas, contendrá los criterios relativos a la conservación de fachadas y cubiertas e instalaciones sobre las mismas (art. 20.2), la catalogación, según la legislación urbanística, de los elementos unitarios que conforman el conjunto, tanto inmuebles edificados como espacios libres exteriores o interiores, $u$ otras estructuras significativas, así como los componentes naturales que lo acompañan, definiendo los tipos de intervención posible (art. 21.1). Mayor interés tienen a nuestros efectos los segundos, es decir, los principios que habrá de asumir el plan urbanístico que incida sobre

(26) Vid. infra sobre este novedoso instrumento al servicio de la rehabilitación urbana. 
un conjunto histórico; así, su conservación exige el mantenimiento de la estructura urbana y arquitectónica, las características generales de su ambiente, considerándose excepcionales las sustituciones de inmuebles, aunque sean parciales, a no ser que con ello se contribuya a la conservación general del conjunto, y siempre manteniendo las alineaciones urbanas existentes (art. 21.3); sólo excepcionalmente el plan podrá permitir remodelaciones urbanas, siempre que impliquen una mejora de sus relaciones con el entorno territorial o urbano o eviten los usos degradantes para el propio conjunto (art. 21:2).

Si antes vimos, en relación con el entorno de los monumentos afectados por un plan urbanístico, una solución un tanto criticable, el legislador cambia el criterio para el otorgamiento de licencias o autorizaciones para realizar obras en los inmuebles declarados conjuntos históricos; en efecto, el artículo 20 distingue según sea el momento en que ha de ser otorgada la licencia de obras, pues si es anterior a la aprobación definitiva del plan, uel otorgamiento de la licencia lo la ejecución de las otorgadas antes de ser incoado el expediente declarativo del conjunto histórico, sitio histórico o zona arqueológica) precisará la resolución favorable de la Administración competente para la protección de los bienes afectados $(y$, en todo caso, no se permitirán alineaciones nuevas, alteraciones en la edificabilidad, parcelaciones ni agregaciones)». La solución es distinta cuando el plan ha sido aprobado definitivamente, en cuyo caso, los órganos municipales competentes autorizarán directamente y sin el concurso posterior de la Administración de defensa del Patrimonio Histórico las obras que desarrollen el planeamiento aprobado y que afecten a los inmuebles, debiendo dar cuenta a la Administración sectorial en el plazo de diez días del otorgamiento de las licencias o autorizaciones.

En nuestra opinión, el legislador ha adoptado un criterio certero: sin un plan aprobado los organismos de defensa del Patrimonio Histórico deben velar por su conservación, autorizando o denegando las obras solicitadas. Una vez aprobado el plan urbanístico, por quedar asumidas en él las determinaciones para la conservación y defensa del conjunto, es la Administración municipal la encargada de su aplicación, con independencia del contenido. 


\section{DECLARACION DE RUINA Y PROTECCION DEL PATRIMONIO HISTORICO}

Para completar lo expuesto acerca de la declaración de ruina, entendemos de utilidad realizar alguna reflexión sobre su funcionamiento en relación con la protección del Patrimonio HistóricoArtístico. Situándonos en la legislación que arranca de la República, se observa que no existe ningún precepto ni en la Ley de 13 de mayo de 1933 ni en la normativa de desarrollo, ni siquiera en la legislación urbanística de donde procede la institución, que ponga expresamente en conexión la declaración de ruina con la protección del Patrimonio Histórico-Artístico. Ante esta realidad es fácil adivinar que nuestros tribunales han tenido que suplir la ausencia de criterios legales en los numerosísimos conflictos planteados por declaraciones de ruina de inmuebles que habían alcanzado la declaración de monumentos histórico-artísticos; en tales circunstancias y con el apoyo que proporcionaban los artículos 17 de la Ley del 33 y 21 de su Reglamento, los órganos judiciales han venido distinguiendo la declaración de ruina, como situación fáctica que los Ayuntamientos han de reconcer a través del expediente correspondiente, $y$ el derribo propiamente dicho, que no tiene por qué seguir necesariamente a aquella declaración si el órgano competente para ello niega la autorización con base en el interés histórico-artístico del edificio que, por ello, es preciso conservar (27).

Solución similar se ha mantenido en los supuestos en que simplemente ha sido incoado expediente de declaración históricoartística; para este caso, el artículo 17 que se acaba de citar proporciona suficiente apoyo a la misma al disponer que «una vez incoado el expediente para la declaración de un edificio como monumento histórico-artístico, no podrá derribarse, realizarse en él obra alguna ni proseguir las obras comenzadas»; de ello se deduce que es posible el desarrollo paralelo de dos expedientes: uno de declaración de ruina y otro de declaración de monumentalidad, quedando sometida la efectiva demolición del inmueble a la autorización sectorial (28).

Por último, cabe plantearse el supuesto límite en que no hay ni declaración de monumento histórico-artístico, ni siquiera ha sido incoado un expediente a tal fin; en estas circunstancias la normal declaración de ruina y su consecuencia típica, el derribo, sólo podría

(27) Son muchas las sentencias del Tribunal Supremo que se pronuncian en este sentido. vid., entre ellas la reciente de 24 de febrero de 1987 (Artículo núm. 3362).

(28) Artículos 23 de la Ley de 1933 y 21 de su Reglamento. 
verse alterada por las condiciones materiales de monumentalidad protegibles reunidas por el edificio al margen de la declaración o incoación formal del expediente; en este caso, lo lógico sería trasladar a este supuesto las soluciones anteriores, aún con los matices que fueran necesarios, es decir, la normal tramitación y, en su caso resolución, del expediente de declaración de ruina, a la vez que se procede a la comunicación por el Municipio o terceros al órgano sectorial competente para que se proceda o no a la declaración histórico-artística del edificio; la jurisprudencia, sin embargo, de forma un tanto sorprendente ha radicalizado su posición si se la compara con la dada a aquellos supuestos en que ya había sido incoado o resuelto el expediente de ruina, pues para el caso ahora analizado ha vinculado la resolución, suspensión o archivo del expediente de ruina a la decisión del órgano de defensa del Patrimonio Histórico; al menos esto es lo que se deduce de la sentencia del Tribunal Supremo de 10 de octubre de 1978 (artículo núm. 3.661), al disponer que:

«... de no existir previa declaración de monumentalidad y tampoco haberse iniciado los trámites para efectuarla ante el órgano central competente, con la sola diferencia, en supuesto ahora examinado, de que constatados en el expediente sobre ruina valores histórico-artísticos deberá el instructor comunicarlos a la Dirección General del Patrimonio Artístico y Cultural a los efectos previstos en el art. 27 párrafo $1 .^{\circ}$ de la Ley de 13 de mayo de 1933, y, según su resultado, es decir, al tenor de la decisión del órgano competente comunicada por aquella Dirección General, resolverá el Ayuntamiento positiva o negativamente la solicitud de declaración del estado ruinoso o bien suspenderá la resolución del procedimiento sobre ruina hasta que recaiga acuerdo de órgano superior si alli se hubiera acordado incoar expediente sobre declaración de monumento a consecuencia de la susodicha participación municipal de presunto valor histórico-artístico del edificio.»

Solamente la necesidad de proceder urgentemente a la demolición exonera a la autoridad municipal a acudir a la Administración de protección del Patrimonio Histórico-Artístico en busca de la autorización para proceder al derripo de un edificio monumental; el fundamento de esta facultad se halla tanto en la legislación urbanística -artículo 183.4 de la Ley del Suelo- como en la normativa reguladora del régimen local, que habilita al Alcalde a adoptar las medidas adecuadas en caso de urgencia y necesidad [artículo 117 del derogado Texto articulado y refundido de 1955 y 
artículo 21.1.j) de la LRBRL actual]; así lo ha señalado el Tribunal Supremo en su reciente sentencia de 8 de mayo de 1987 (Artículo núm. 3564), respaldando la legalidad de la actuación del Alcalde de Sevilla:

"... al ordenar la demolición del edificio a la vista de los informes técnicos $y$ jurídicos que se emitieron, con urgencia, bajo la responsabilidad de la autoridad que lo ordenó y sin que en tal caso, frente a la situación de grave daño del inmueble con la premura de tiempo en la demolición para evitar daños mayores, exigiesen de ninguna otra medida, ni por tanto la autorización de los organismos del Patrimonio Artístico, a los que se dio cuenta de la situación de ruina inminente, habiéndose procedido por el propietario en la forma ordenada por la Autoridad competente ante la excepcional situación de la construcción lo que, como así lo entendió la sentencia, impide que pueda considerarse como demolición clandestina...»

En líneas generales, la nueva regulación del Patrimonio Histórico no se aparta de la interpretación jurisprudencial dada a la precedente normativa. Tal es así que se permite la incoación y resolución del expediente de declaración de ruina sobre un inmueble de Interés Cultural, estando la Administración sectorial legitimada para intervenir como interesado en ese expediente, reteniendo en todo caso esta Administración la competencia para autorizar o denegar la demolición material del edificio (artículo 24, 1 y 2 en relación con el 37.1, ambos de la Ley 16/1985). También contempla esta Ley la situación de urgencia y peligro inminente en que pudiera encontrarse el Bien de Interés Cultural, circunstancia que permite la ejecución de las obras que por fuerza mayor hubieran de realizarse; incluso son admitidos actos de demolición siempre que sean estrictamente necesarios para la conservación del inmueble, cuando sean autorizados por la autoridad competente para la ejecución de esta Ley (artículo 24.3 en relación con el 16.2). Como fácilmente se puede observar, el legislador no ha previsto, al menos expresamente, facultad excepcional alguna en favor del Alcalde en caso de ruina inminente; en todo caso, entiendo que, al igual que tampoco se preveía en la Ley de 1933, el Alcalde en este caso como en todos aquellos supuestos en que se ponga en peligro la seguridad ciudadana, puede hacer uso de la genérica competencia que le atribuye el citado artículo 21.1.j) de la LRBRL, es decir, «adoptar personalmente, y bajo su responsabilidad, en caso de catástrofe o infortunios públicos o grave riesgo de los mismos, las 
medidas necesarias $y$ adecuadas», medidas cuya ponderación queda claramente plasmada en la necesidad y adecuación.

Para terminar, poco hay que añadir a la declaración de ruina en relación con inmuebles que no hayan sido declarados de Interés Cultural. La concurrencia en éstos de unos valores de los que menciona el artículo $1 .^{\circ}$ de la Ley nos remite al artículo 37.2, ya analizado desde otra perspectiva; con él, como se vio, se habilita a la Administración para impedir el derribo -lo que hay que poner en relación con la ruina ya declarada- y resolver en el plazo máximo de treinta días otorgando autorización para demoler, o bien en favor de la incoación del expediente de declaración de Bien de Interés Cultural.

\section{VALORACION}

Es justo reconocer que la normativa recientemente aprobada supone un importante avance sobre la precedente. Como se ha tratado de demostrar, los males de que adolecía, es decir, la falta de apoyo financiero, la desconexión con los instrumentos de planeamiento urbanístico y la tradicional perspectiva selectiva en que se situó, han sido subsanados con importantes medidas de fomento y una continua remisión a los mecanismos urbanísticos, favoreciendo con ello el abandono de la protección aislada de ciertos bienes a que se reducía la labor tuitiva de los organismos de protección del Patrimonio Histórico Español.

Si esto es así, y aún a falta de suficientes datos para poder valorar el funcionamiento real de las instituciones que prevé la Ley $16 / 1985$, de 25 de junio, y su normativa complementaria, difícilmente se puede negar la mejor predisposición de estas normas para atajar el progresivo deterioro del legado histórico si se las compara con la legislación cincuentenaria a la que sustituye. Sin embargo, nada de lo dicho sirve para evitar la objeción de fondo de que se hace acreedora esta normativa, no por su incapacidad para cumplir sus fines institucionales, de lo que ya nos hemos hecho eco con una positiva consideración, sino por su inadecuación para subvenir a unas necesidades planteadas por la sociedad en la actualidad que sobrepasan sus posibilidades. En nuestro criterio, el conjunto de medidas que contienén estas normas van dirigidas a la protección de un sector del patrimonio edificado, especialmente cualificado por unas características que pueden llegar a ser reconocidas expresamente por la Administración y que sugieren una protección muy intensa del inmueble, pero al margen queda la

REVISTA DE ESTUDIOS.-10 
mayoría de la riqueza inmobiliaria del país que no encuentra tutela alguna en el articulado de esta Ley, por lo que, a lo sumo, en ella sólo puede reconocerse una limitada eficacia para servir a la conservación y recuperación del patrimonio edificado español en su integridad. 
REALA-1988, núm. 239. QUINTANA LOPĖZ, TOMAS. LA CONSERVACION DE LAS EDIFICACIONE...

REALA-1988, núm. 239. QUINTANA LOPEZ, TOMAS. LA CONSERVACION DE-LAS EDIFICACIONE... 